\title{
Féeries
}

Études sur le conte merveilleux, XVII $-\mathrm{XIX}{ }^{\mathrm{e}}$ siècle

\section{Petit-Poucet rêveur. La poésie des contes} merveilleux

Paris, José Corti, coll. « Collection Merveilleux » n 53, 2017, 200 p.

\section{Jean-Paul Sermain}

\section{(2) OpenEdition}

\section{Journals}

Édition électronique

URL : http://journals.openedition.org/feeries/2093

DOI : $10.4000 /$ feeries.2093

ISSN : 1957-7753

\section{Éditeur}

UGA Éditions/Université Grenoble Alpes

Édition imprimée

ISBN : 978-2-37747-075-4

ISSN : 1766-2842

\section{Référence électronique}

Jean-Paul Sermain, «Petit-Poucet rêveur. La poésie des contes merveilleux », Féeries [En ligne], 15

2018, mis en ligne le 27 février 2019, consulté le 24 septembre 2020. URL : http://

journals.openedition.org/feeries/2093; DOI : https://doi.org/10.4000/feeries.2093

Ce document a été généré automatiquement le 24 septembre 2020.

(c) Féeries 


\section{Petit-Poucet rêveur. La poésie des contes merveilleux}

Paris, José Corti, coll. « Collection Merveilleux » n 53, 2017, 200 p.

Jean-Paul Sermain

\section{RÉFÉRENCE}

Nicole Belmont, Petit-Poucet rêveur. La poésie des contes merveilleux, Paris, José Corti, coll. «Collection Merveilleux » ${ }^{\circ}$ 53, 2017, 200 p.

1 Cet ouvrage paraît dans la très riche collection, de textes et d'études du récit merveilleux, fondée par F. Raphoz chez Corti, qui s'inscrit bien dans la tradition de cette illustre maison. C'est un recueil d'articles, une série d'études revenant souvent sur les mêmes points et reliés par quelques idées directrices assez simples. Elles s'organisent dans deux directions. La principale et la plus convaincante cherche à cerner et à caractériser la production orale des contes merveilleux ancrés dans les sociétés traditionnelles par ailleurs en voie d'extinction (le monde agricole français s'est réduit démesurément et repose sur des pratiques et une économie intégrées aux échanges mondiaux, elle a assimilé l'école et les nouveaux médias). N. Belmont s'intéresse donc aux témoignages d'un monde disparu : comme elle le remarque à de nombreuses reprises en s'appuyant sur les travaux bien connus de W. Ong, le mode du conte merveilleux oral est celui d'une performance singulière qui s'adresse à son public dans une situation et à un moment donnés. N. Belmont, qui s'appuie sur les transcriptions principalement de la fin du $\mathrm{xIX}^{\mathrm{e}}$ et du début $\mathrm{du} \mathrm{xx}^{\mathrm{e}}$ siècle, relève la difficulté de transcrire l'oralité et les mutilations de la plupart des transcriptions pour en assurer la lisibilité. Le conte merveilleux oral peut éventuellement être approché aujourd'hui comme un spectacle très éloigné des cultures où il est né, sinon il n'existe que dans les livres comme celui de N. Belmont qui le présente, le raconte et surtout le célèbre avec chaleur: dans une médiation savante et lyrique. N. Belmont lui accorde plusieurs significations : il est un moyen pour une collectivité, par l'entremise d'un de 
ses membres compétents, de maîtriser les grandes déterminations de la vie (naissance, mariage, filiations, morts) ; il saurait exprimer l'inconscient (ici ramené à la description freudienne, par exemple p. 13) et lui parler ; il est aussi capable de saisir une situation sociale (un des articles les plus intéressants concerne les récits de la Nièvre et du Morvan illustrant la situation des nourrices pauvres) ; il est porté par l'itinéraire joyeux du héros tel que Propp et Jolles l'ont décrit. Il faut donner une place toute spéciale à ce qui pour N. Belmont est l'élément le plus fort du conte merveilleux et que le beau titre emprunté à Rimbaud veut annoncer : il repose sur des images mentales qui s'imposent à la mémoire et condensent des significations à la fois anthropologiques et narratives. "Le conte mémorisé n'est pas une suite de mots et de phrases comme dans le "par cœur". C'est un itinéraire mental, fait d'images fortes apparaissant successivement le long du trajet. Ce n'est pas un texte, c'est une aventure, l'itinéraire du héros ou de l'héroïne dans le cas des contes merveilleux, ponctué d'images mentales très vigoureuses, plus fortes encore que des images figurées (comme les illustrations des livres de contes par exemple) et que le conteur - qui les voit se dérouler - doit les verbaliser [sic] au fur et à mesure.» (p. 148) On notera ici un exemple des négligences de rédaction trop nombreuses qu'aucune relecture n'a corrigées (comme dans les p. 27 et 156). N. Belmont s'intéresse à ce processus de mémorisation en s'appuyant sur des propositions poétiques de Max Lüthi, par exemple l'idée d'un motif aveugle (sans rapport avec le conte) et d'un motif écourté (c'est-à-dire simplifié, mutilé). On retiendra dans les objets singuliers intégrés à ce discours général des études portant sur des versions du "Petit-Poucet », sur "Barbe bleue », et sur le recueil des frères Grimm. N. Belmont leur reproche d'avoir voulu acclimater les contes populaires en les réservant à l'enfance. Un deuxième versant de cet ouvrage, un peu vain et moins plaisant, consiste en effet à utiliser le conte littéraire merveilleux comme contremodèle dépourvu de toutes les vertus du conte oral, et à contester les chercheurs qui ont voulu les inscrire dans la tradition littéraire comme R. Bottigheimer, U. Heidmann et J.-M. Adam, en mettant certaines formules radicales de ces auteurs en exergue. Distinguons deux questions. Le conte merveilleux écrit constitue un des genres littéraires anciens et féconds dont de nombreuses œuvres atteignent les sommets de la littérature, et ils en possèdent toutes les propriétés d'intensité, de style, de transmission nationale et universelle. Il est donc tout à fait légitime de les lire et de les interpréter comme des textes littéraires éminents et devenus classiques. Cela n'affecte en rien l'intérêt qu'on peut prendre à reconstituer des pratiques orales et à conserver les témoignages érigés en archives. L'autre question est plus complexe : elle concerne les va-et-vient entre l'oral et l'écrit que N. Belmont n'envisage que dans un sens, contrairement à Catherine Velay-Vallantin qui n'est pas citée une seule fois! $\mathrm{N}$. Belmont reproche aux spécialistes du conte littéraire de méconnaître, de minorer, de refuser ce que le conte littéraire doit au conte merveilleux oral. Ce reproche ne s'adresserait qu'à ceux qui veulent en faire la généalogie et, d'autre part, il supposerait qu'on puisse établir clairement l'état des contes merveilleux oraux dans l'Antiquité, au Moyen Âge, du XVI ${ }^{e}$ au XVIII ${ }^{e}$ siècle, ce qui n'est pas le cas. Il faut au mieux se contenter d'une présence vague ramenée à une économie générale (celle que vise N. Belmont) et à des situations narratives. On peut donc établir un lien "en gros». De nombreuses études y sont sensibles dans la mesure où elles relient le conte écrit à des substrats psychiques (comme J.Bellemin-Noël) ou à des situations historiques (comme B. Bricout), qui seraient les mêmes que pour le conte oral. Les liaisons thématiques sont également faciles à établir. Mais par ailleurs les modes de formation et de transmission, 
de production et de réception, sont totalement différents comme l'explique aussi tout $\mathrm{du}$ long N. Belmont, les deux genres (oral et écrit) appellent donc des types d'appréciation, de lecture et d'interprétation bien séparés. Le problème du conte oral actuel n'est pas d'être en dehors de la littérature écrite, d'autant que les nouveaux médias ont étendu l'empire de modes non écrits du récit et de l'image, mais de venir de cultures qui se rétrécissent et qui ont quasiment disparu dans les pays occidentaux. De cet ennemi bien réel, N. Belmont ne dit mot. Retenons donc de son livre sa ferveur, son culte de l'image "agissante", son évocation enthousiaste de quelques contes entrevus dans les archives de l'oralité.

\section{AUTEURS}

\section{JEAN-PAUL SERMAIN}

Université Sorbonne nouvelle - Paris 3 